\title{
FOLATO E SEU PAPEL NA DEPRESSÃO
}

\section{FOLATE AND ITS ROLE IN DEPRESSION}

\author{
Marcelo Luis da Silva*1, João Vitor Pelizzari² ${ }^{2}$ Vagner Fagnani Linartevichi ${ }^{3}$ \\ ${ }^{1}$ Acadêmico de Medicina, Centro Universitário Fundação Assis Gurgacz (FAG). ${ }^{2}$ Médico \\ Psiquiatra, Docente do Curso de Medicina, Centro Universitário Fundação Assis Gurgacz \\ (FAG). ${ }^{3}$ Doutor, Docente do Curso de Medicina, Centro Universitário Fundação Assis Gurgacz \\ (FAG). * Autor correspondente: marceloluismed@gmail.com https://orcid.org/0000-0003-2940- \\ 6015
}

\section{RESUMO}

Introdução: Transtornos depressivos são bastante prevalentes, com grande incapacidade laborativa e social. Podem ter caráter recidivante e persistente ao longo do tempo. A deficiência de folato é potencialmente prevenível e ainda carente de grandes estudos de seu papel na depressão e outros transtornos de saúde mental. Objetivos: Avaliar a associação da deficiência de folato com depressões graves e refratárias ao tratamento, frequentemente descritas com evidências atuais. Metodologia: Os artigos foram selecionados por meio da base de dados PubMed. Resultados: Níveis deficientes de folato são resultantes da baixa ingestão, deficiente absorção intestinal e polimorfismo genético com a forma ineficiente da enzima responsável em converter o folato/ácido fólico em sua forma com atividade biológica, o L-metilfolato. O folato é indispensável na síntese de neurotransmissores ligados aos processos depressivos - serotonina, noradrenalina e dopamina, além participar de forma epigenética na regulação da expressão gênica. Conclusões: apesar da evidência positiva da associação da deficiência de folato com transtornos depressivos, ainda são necessários estudos adicionais para definir quando e quais pacientes podem ser beneficiados com a terapia antidepressiva em associação ao uso de folato.

Palavras chave: Antidepressivos, deficiência de ácido fólico, psicofarmacologia, polimorfismo genético.

\begin{abstract}
Introduction: Depressive disorders are quite prevalent, with great labor and social incapacity. They may be recurrent and persistent over time. Folate deficiency is potentially preventable and still lacking in large studies of its role in depression and other mental health disorders. Objectives: To evaluate the association of folate deficiency with severe and treatment-refractory depressions, often described with current evidence. Methods: Data were selected through PubMed database. Results: Poor folate levels result from low ingestion, poor intestinal absorption and genetic polymorphism with the inefficient form of the enzyme responsible for converting folate / folic acid into its biologically active form, L-methylfolate. Folate is indispensable in the synthesis of neurotransmitters linked to depressive processes - serotonin, noradrenaline and dopamine, besides epigenetically participating in the regulation of gene expression. Conclusions: Despite the positive evidence of the association of folate deficiency with depressive disorders, additional studies still needed to determine when and
\end{abstract}


which patients may benefit from antidepressant therapy in association with folate use.

Keywords: Antidepressive agents, Folic acid deficiency, Psychopharmacology, Genetic polymorphism.

\section{INTRODUÇÃO}

O folato é uma vitamina hidrossolúvel do complexo B (vitamina B9), naturalmente encontrado em vegetais com folhas verde escuras, sendo obtido exclusivamente a partir da dieta, não é sintetizado pela via de novo nos organismos humanos. Ácido fólico é a forma sintética mais estável do folato utilizada em alimentos fortificados e suplementos (LIEW, 2016). Possui funções biológicas diversas e fundamentais, como regular a expressão gênica, proliferação e sobrevivência celular (HERRERA, MUÑOZ e PARRA, 2016).

A associação entre suplementação de ácido fólico e seu efeito no período gestacional como medida para prevenção de defeitos do tubo neural já foi bem estabelecida, porém o papel em outras doenças ainda são pouco claros e por vezes contraditórios (LIEW, 2016).

A depressão é um transtorno mental prevalente e debilitante, que pode apresentar um quadro clínico persistente e recidivas ao longo da vida. Antidepressivos são recomendados para o tratamento, sobretudo na depressão moderada a grave, porém apenas metade dos pacientes apresentam resposta satisfatória com utilização desses fármacos. Associar 0 ácido fólico ao tratamento pode melhorar a eficácia, pois pacientes depressivos geralmente apresentam deficiência de folato e esta se correlaciona com a gravidade e refratariedade à terapêutica tradicional. $O$ folato é diretamente ligado à síntese de neurotransmissores responsáveis em grande parte pelo transtorno depressivo (BEDSON et al, 2014). Deste modo, o presente estudo teve por objetivo fazer uma revisão da literatura sobre a correlação entre o folato e a depressão maior.

\section{METODOLOGIA}

Foi realizada revisão bibliográfica nas bases de dados Scientific Electronic Library Online (Scielo), Medline Complete e complementação com artigos adicionais das bases PubMed NCBI e Google Scholar. Foram selecionadas referências publicadas nos últimos 10 anos (2009 a 2019), disponíveis na íntegra, correlacionando saúde mental, depressão e sua associação com redução dos níveis de folato (em suas diferentes formas: folato, ácido fólico e Lmetilfolato), disponíveis como revisões sistemáticas, metanálises e pesquisas. Foram excluídas publicações duplicadas nas bases de dados, disponíveis apenas na forma de resumos, editoriais, artigos de opinião. A discussão promovida com base na bibliografia selecionada buscou embasar de forma científica os possíveis efeitos do ácido fólico/folato nos transtornos depressivos.

\section{RESULTADOS E DISCUSSÃO}

Transtornos depressivos são definidos pelo Manual Diagnóstico e Estatístico de Transtornos Mentais, da Associação Americana de Psiquiatria 
(DSM - 5), como um conjunto de transtornos que apresentam em comum: "humor triste, vazio ou irritável, acompanhado de alterações somáticas e cognitivas que afetam significativamente a capacidade de funcionamento do indivíduo". O que diferencia entre as formas clínicas de depressão, são a duração, momento da apresentação ou etiologia presumida (DSM-5). A depressão afeta 121 milhões de pessoas no mundo sendo responsável pelo quarto lugar em gastos totais com doenças. Em 2020 segundo a Organização Mundial de Saúde (OMS), deverá ser a segunda causa no ranking de Anos de Vida Perdidos Ajustados por Incapacidade para todas as faixas etárias, que calcula o total de anos perdidos em determinada população, por incapacidade ou morte prematura (REDDY, 2010).

A prevalência de depressão em adultos no Brasil, conforme dados da Pesquisa Nacional de Saúde (PNS) de 2013 é maior em mulheres (10,9\%) do que em homens (3,9\%). A faixa etária de maior prevalência entre adultos é entre 60 a 64 anos (11,1\%) e a menor na faixa de 18 a 29 anos (3,9\%). Segundo a PNS 7,6\% da população adulta já recebeu diagnóstico de depressão em algum momento da vida (STOPA et al, 2013). Transtornos depressivos frequentemente recidivam, com mais de $30 \%$ dos pacientes apresentando um segundo episódio após remissão dos sintomas, dentro de 2 anos após o tratamento (FARAH E SHELTON, 2009).

Não são observadas diferenças significativas de efetividade entre as principais classes de antidepressivos, estando a decisão de qual droga utilizar baseada em fatores individuais, como aceitação, sintomatologia, idade, toxicidade, custo e utilização de outras medicações concomitantes (AGUIAR et al, 2011). Nas formas leves de depressão não é consenso que a utilização de medicamentos antidepressivos apresente vantagens terapêuticas para todos os pacientes. Nos pacientes de moderada a grave intensidade, a utilização de diferentes fármacos antidepressivos apresenta vantagens terapêuticas comprovadas, com diferentes estudos exibindo resultados semelhantes e reprodutíveis (BAGHAl et al, 2011).

Apesar da utilização de medicamentos antidepressivos ser a modalidade terapêutica mais utilizada e estudada no tratamento dos transtornos depressivos, sua eficácia é limitada com taxas de remissão entre $42 \%$ e $70 \%$ variando entre diferentes estudos. Cerca de $30 \%$ podem permanecer refratários após múltiplas tentativas terapêuticas (ROCHA et al, 2013; FARAH E SHELTON, 2009). Somente $30 \%$ a $50 \%$ dos pacientes terão uma boa resposta inicial ao tratamento em monoterapia com medicamento antidepressivo, com a maioria apresentando resposta parcial ou sem resposta. Para manter o efeito obtido, aumentar a responsividade e remissão da depressão frequentemente é necessário substituir ou adicionar um segundo fármaco. (FARAH E SHELTON, 2009; BEDSON et al, 2014).

Folato é um micronutriente essencial, com papel de cofator indispensável como doador de grupo metil para inúmeras reações metabólicas. Baixos níveis séricos podem decorrer de insuficiente ingestão através da dieta, baixa absorção intestinal do folato ingerido e alterações no metabolismo, por defeitos genéticos ou interações com drogas. Diversas patologias tem sido relacionadas com deficiências do folato, como defeitos do tubo neural, doença cardiovascular, câncer e disfunções cognitivas (SCAGLIONE E PANZAVOLTA, 2014).

O folato apresenta um mecanismo de sinalização com especificidade para o sistema nervoso central, mediado pelos receptores de folato. Dessa forma, é 
indispensável nas etapas de formação, maturação e manutenção da saúde neuronal. O equilíbrio da disponibilidade do folato é necessário desde os estágios da formação intrauterina do sistema nervoso até a manutenção de homeostase e reparo dos neurônios na vida adulta e senilidade. Desequilíbrios na disponibilidade desse micronutriente causam alterações de saúde mental e potencialmente doenças neurodegenerativas (BALASHOVA, VISINA e BORODINSKY, 2018).

Baseado nisso, diversos países tem suplementado ou fortificado alimentos com alguma das formas de folato: ácido fólico, folínico ou L-metilfolato (5-metiltetrahidrofolato), sendo que esta última forma apresenta a vantagem de ocorrer naturalmente no organismo e possuir atividade biológica, enquanto a forma sintética, o ácido fólico necessita de biotransformação. O L-metilfolato possui boa absorção em alterações do pH gastrointestinal, menor interação com fármacos que inibem a enzima dihidrofolato redutase e sua biodisponibilidade não é alterada por defeitos metabólicos, como polimorfismo enzimático da metiltetrahidrofolato redutase (MTHFR). O uso do L-metilfolato também previne potenciais efeitos circulatórios do ácido fólico não convertido, indicando ser a forma preferível para suplementação (SCAGLIONE E PANZAVOLTA, 2014).

Quando a fortificação alimentar com ácido fólico é empregada, são utilizadas principalmente as farinhas de trigo e milho. A adição alimentar do folato sintético melhora os níveis sanguíneos e eritrocitários de folato, porém a ingestão em forma de comprimidos com dose de $5 \mathrm{mg}$ semanal, adicionalmente melhorou o hematócrito das pacientes avaliadas, sugerindo uma maior eficácia terapêutica da suplementação oral comparada à fortificação alimentar. (SÁNCHEZ et al, 2011). Quando ocorre a decisão clínica de suplementar folato, a dose máxima deve levar em conta o total ingerido na dieta diária, e a dose do suplemento. $O$ consumo máximo deve respeitar o limite superior tolerável de ingestão diário de $1000 \mathrm{mcg}$, sendo valores de suplementação de 400 a $700 \mathrm{mcg}$ diários considerados seguros e mantinham o folato sérico dentro de doses terapêuticas (SANTOS et al, 2013).

A ingestão adequada de folato através da dieta, associa-se abaixa prevalência de sintomas depressivos em jovens de 12 a 15 anos, de ambos os sexos (MURAKAMI et al, 2010). Em idosos o folato sérico baixo foi positivamente associado com sintomas depressivos, sem diferença entre homens e mulheres (PETRIDOU et al, 2016). Níveis reduzidos de folato sérico foram positivamente associados ao aumento da prevalência de sintomas depressivos, sobretudo no sexo masculino. A elevação da homocisteína sérica, sugestiva de deficiência crônica de folato também foi positivamente associada a esse grupo e apresenta potencial toxicidade neuronal, contribuindo para a patogênese da depressão (NANRI, et al 2010). Níveis sub-ótimos de folato sanguíneo associam-se a depressões mais graves, com início tardio de melhora, pior resposta terapêutica e resistência ao tratamento (FARAH E SHELTON, 2009).

Além da ingestão insuficiente através da dieta, o polimorfismo genético da enzima MTHFR também pode ser fator gerador da deficiência de folato, pois a atividade enzimática é necessária para converter em sua forma biologicamente ativa. (HERRERA, MUÑOZ e PARRA, 2016). A mutação C677T consiste na substituição de alanina por valina no códon 677 da MTHFR, podendo a população ser homozigota normal CC, heterozigota CT ou TT para o alelo polimórfico. O prevalência do alelo TT varia em diferentes populações e apresenta evidências de estar diretamente relacionada com diminuição do folato 
nesses indivíduos (SÁNCHEZ et al, 2011). Mulheres grávidas com o alelo MTHFR 677TT manifestaram piora nos quadros depressivos e sintomas mais graves de depressão sobretudo no segundo trimestre gestacional, quando comparadas aos alelos CC ou CT. Essas gestantes apresentaram ainda alteração de metilação, com expressão reduzida na mãe e no recém-nascido do gene promotor SLC6A4, que codifica o transportador transmembrana de serotonina (DEVLIN et al, 2010).

A variante C677T desta enzima parece interferir diretamente nas concentrações sérica e eritrocitária do micronutriente, além de atuar no clico da metionina (HERRERA, MUÑOZ e PARRA, 2016). A metionina é uma aminoácido essencial e seu metabolismo produz por desmetilação a homocisteína, cujo acúmulo aumenta o risco de excitotoxicidade e dano oxidativo neuronal. O Lmetilfolato é utilizado como doador metil para a remetilação em metionina. A hiperhomocisteinemia ainda produz metabólitos neurotóxicos instáveis, como o ácido homocisteico e ácido cisteínico sulfínico que atuam como agonistas do receptor N-metil-D-aspartato (NMDA), com efeitos neurotóxicos sobre neurônios dopaminérgicos, participando da fisiopatologia da depressão no espectro dopaminérgico (BHATIA E SINGH, 2015). A hiperhomocisteinemia é marcador da deficiência crônica de folato, apresentando níveis sanguíneos inversamente proporcionais (LOUREIRO et al, 2010).

O acúmulo da homocisteína por alteração genética da MTHFR C677T diminui globalmente a síntese dos neurotransmissores dopamina, norepinefrina, epinefrina (catecolaminas) e na serotonina (5-HT), levando a depressão por diminuição da síntese dos neurotransmissores, além da toxicidade direta aos neurônios dopaminérgicos (BHATIA E SINGH, 2015). In vitro a hiperhomocisteinemia por deficiência de folato também reduz a proliferação de células neuronais e sensibiliza para o processo de apoptose (AKCHICHE et al, 2012).

A metilação do DNA utilizando o grupo metil advindo do folato, atua diretamente na regulação e expressão gênica de forma epigenética, assim características genéticas herdadas podem ou não ser expressas clinicamente. Polimorfismos genéticos, folato dietético, fatores ambientais e socioeconômico afetam os níveis de metilação do DNA, impactando diretamente na expressão dos fenótipos. As diferenças de metilação de DNA além de apresentarem características observáveis clinicamente são potenciais biomarcadores para as disparidades de saúde entre as diferentes populações humanas (KADER E GHAl, 2017). A disponibilidade de folato também interfere diretamente na expressão correta de S-adenosil metionina (SAM), que regula de forma epigenética a correta expressão da Catecol-O-Metiltransferase (COMT). A COMT atua no metabolismo nas catecolaminas relacioadas aos transtornos depressivos (KUZELICKI, 2016).

O transporte vesicular neuronal é drasticamente afetado na deficiência de folato com hiperhomocisteinemia, o que justifica parte da fisiopatologia da depressão, diretamente relacionada com exocitose de vesículas contendo neurotransmissores (AKCHICHE et al, 2012).

Pacientes com depressão, esquizofrenia e demência, com frequência apresentam níveis séricos mais baixos de folato, quando comparados com indivíduos sem esses transtornos psiquiátricos. A associação do folato com a terapia com antidepressivos inibidores seletivos da receptação da serotonina (ISRS) ou inibidores seletivos da receptação da serotonina e noradrenalina 
(ISRSN) tem demonstrado aumento da eficácia dos fármacos antidepressivos e início de ação mais rápido. Mesmo o uso isolado do L-metilfolato em monoterapia tem evidência de propriedades antidepressivas. Apesar do conhecido potencial terapêutico do folato na saúde mental, ainda não existe consenso sobre quais pacientes podem ser beneficiados com seu uso na prática clínica (MARTONE, 2018).

Em pacientes com sintomas depressivos graves, a utilização de folato não melhorou sintomas em curto prazo (dias a semanas), porém o uso prolongado (semanas a anos) diminuiu o risco de recidiva e também o aparecimento de sintomas clinicamente significativos em pessoas de risco (ALMEIDA, FORD e FLICKER, 2015). Pacientes portadores de Transtorno de Conduta Alimentar, ao receberem suplementação com ácido fólico, apresentaram melhores resultados em testes para avaliação de função cognitiva e depressão (KOHEN et al, 2013). O estabelecimento de uma dieta adequada, com otimização de compostos nutricionais específicos, dentre eles o folato, como estratégia preventiva ou terapêutica é desejável e eficaz para pacientes com transtornos depressivos. Por ser uma abordagem prática e não estigmatizante pode ser utilizada de forma aditiva ao tratamento antidepressivo convencional (LANG et al, 2015).

\section{CONSIDERAÇÕES FINAIS}

A provável correlação etiológica da deficiência de folato como causa potencialmente prevenível dos transtornos depressivos, sugere estudos prospectivos ou ensaios randomizados e com grandes amostras populacionais para melhor compreensão. Apesar da forte evidência da correlação, é necessário determinar quais indivíduos serão beneficiados e qual a dose adequada para recomendar a suplementação de ácido fólico, de forma terapêutica ou preventiva.

O conhecimento da prevalência populacional da deficiência de folato e frequência da variante genética alterada da MTHFR C677T pode ser útil como preditivo de formas refratárias de depressão em determinado grupo populacional.

A compreensão sobre o folato e a regulação epigenética através da metilação do DNA, pode ser potencial biomarcador de saúde. O conhecimento dessa relação permitiria a estratificação de risco e prevenção de doenças, dentre elas os transtornos depressivos, identificando os pacientes que serão parcialmente responsivos ou mesmo refratários à terapia convencional.

\section{REFERÊNCIAS}

AGUIAR, C. C; CASTRO, T. R.; CARVALHO, A. F.; VALE, O. C.; SOUSA, F. C.; VASCONCELOS, S. M. Drogas Antidepressivas. Acta Med Port, 24: 091-098, 2011.

AKCHICHE, N.; BOSSENMEYER-POURIÉ, C.; KEREK, R.; MARTIN, N.; POURIÉ, G.; KOZIEL, V.; HELLE, D.; ALBERTO, J.; ORTIOU, S.; CAMADRO, J.; LÉGER, T.; GUÉANT, J.; DAVA, J. Homocysteinylation of neuronal proteins contributes to folate deficiency-associated alterations of differentiation, vesicular transport, and plasticity in hippocampal neuronal cells. The FASEB Journal 
Article fj.12-205757. Published online June 19, 2012. https://doi.org/10.1096/fi.12-205757

ALMEIDA, O. P.; FORD, A. H.; FLICKER, L. Systematic review and metaanalysis of randomized placebo-controlled trials of folate and vitamin B12 for depression. International Psychogeriatrics, 27(05), 727-737, 2015. https://doi.org/10.1017/S1041610215000046

AMERICAN PSYCHIATRIC ASSOCIATION Manual diagnóstico e estatístico de transtornos mentais: DSM - 5. 5. ed. - Porto Alegre: Artmed, 2014.

BAGHAI, T. C.; BLIER, P.; BALDWIN, D. S.; BAUER, M.; GOODWIN, G. M.; FOUNTOULAKIS, K. N.; KASPER, S.;. LEONARD, B. E.; MALT, U. F.; STEIN, D.; VERSIANI, M.; MÖLLER, H. J. General and comparative efficacy and effectiveness of antidepressants in the acute treatment of depressive disorders: a report by the WPA section of pharmacopsychiatry. Eur Arch Psychiatry Clin Neurosci, 261 (Suppl 3): S207-S245, 2011. https://doi.org/10.1007/s00406-011$\underline{0259-6 .}$.

BALASHOVA, O. A.; VISINA, O.; BORODINSKY, L. N. Folate Action in Nervous System Development and Disease. Develop Neurobiol, 78: 391-402, 2018. https://dx.doi.org/10.1002\%2Fdneu.22579

BEDSON, E.; BELL, D.; CARR, D.; CARTER, B.; HUGHES, D.; JORGENSEN, A.; LEWIS, H.; LLOYD, K.; MCCADDON, A.; MOAT, S.; PINK, J.; PIRMOHAMED, M.; ROBERTS, S.; RUSSELL, I.; SYLVESTRE, Y.; TRANTER, R.; WHITAKER, R.; WILKINSON, C.; WILLIAMS, N. Folate Augmentation of Treatment--Evaluation for Depression (FolATED): randomised trial and economic evaluation. Health Technol Assess, Jul; 18 (48): vii-viii, 1-159, 2014. https://doi.org/10.3310/hta18480

BHATIA, P.; SINGH, N. Homocysteine excess: delineating the possible mechanism of neurotoxicity and depression. Fundamental \& Clinical Pharmacology, 29 522-528, 2015. https://doi.org/10.1111/fcp.12145

DEVLIN, A. M.; BRAIN, U.; AUSTIN, J.; OBERLANDER, T. F. Prenatal Exposure to Maternal Depressed Mood and the MTHFR C677T Variant Affect SLC6A4 Methylation in Infants at Birth. Plos One, 5(8): e12201, 2010. https://doi.org/10.1371/journal.pone.0012201

FARAH, A.; SHELTON, R .C. The Role Of L-Methylfolate In Depressive Disorders. CNS Spectrums, 14:1 (Suppl 2), 2009.

HERRERA, M. J.; MUÑOZ, A. M.; PARRA, B. E. S. Factores determinantes del estado nutricional del folato y el rol de la variante genética C677T de la enzima metileno tetrahidrofolatoreductasa (MTHFR). Rev Chil Nutr Vol. 43, №4, 2016. http://dx.doi.org/10.4067/S0717-75182016000400001 
KADER, F.; GHAI, M. DNA methylation-based variation between human populations. Mol Genet Genomics, 292:5-35, 2017. https://doi.org/10.1007/s00438-016-1264-2

KOHEN, V. L.; CANDELA, C. G.; MILLA, S. P.; SASTRE, B. A.; HEMANZ, A.; BERMEJO, L. A. A pilot study of folk acid supplementation for improving homocysteine levels, cognitive and depressive status in eating disorders. Nutr Hosp, May-Jun; 28 (3): 807-15, 2013. https://doi.org/10.3305/nh.2013.28.3.6335

KUZELICKI, N. K. S-Adenosyl Methionine in the Therapy of Depressionand Other Psychiatric Disorders. Drug Dev. Res.77: 346-356, 2016. https://doi.org/10.1002/ddr.21345

LANG, U. E.; BEGLINGER, C.; SCHWEINFURTH, N.; WALTER, M.; BORGWARDT, S. Nutritional Aspects of Depression. Cell Physiol Biochem, 37:1029-1043, 2015. https://doi.org/10.1159/000430229

LIEW, S. C. Folic acid and diseases - supplement it or not? Rev Assoc Med Bras; 62(1): p. 90-100, 2016. https://doi.org/10.1590/1806-9282.62.01.90

LOUREIRO, S. O.; ROMÃO, L.; ALVES, T.; FONSECA, A.; HEIMFARTH, L.; MOURA NETO, V.; WYSE, A. T.; PESSOA-PUREUR, R. Homocysteine induces cytoskeletal remodeling and production of reactive oxygen species in cultured cortical astrocytes. Brain Res, Oct 8; 1355:151-64, 2010. https://doi.org/10.1016/i.brainres.2010.07.071

MARTONE G. Enhancement of recovery from mental illness with L-methylfolate supplementation. Perspect Psychiatr Care, 54:331-334, 2018. https://doi.org/10.1111/ppc. 12227

MURAKAMI, K.; MIYAKE, Y.; SASAKI, S.; TANAKA, K.; ARAKAWA, M. Dietary Folate, Riboflavin, Vitamin B-6, and Vitamin B-12 and Depressive Symptoms in Early Adolescence: The Ryukyus Child Health Study. Psychosomatic Medicine, 72:763-768, 2010.

NANRI, A.; MIZOUE, T.; MATSUSHITA, Y.; SASAKI, S.; OHTA, M.; SATO, M.; MISHIMA, N. Serum folate and homocysteine and depressive symptoms among Japanese men and women. European Journal of Clinical Nutrition, 64, 289-296, 2010. https://doi.org/10.1038/ejcn.2009.143

PETRIDOU, E. T.; KOUSOULISA, A. A.; MICHELAKOSA, T.; PAPATHOMAA, P.; DESSYPRISA, N.; PAPADOPOULOSB, F .C.; STEFANADIS, C. Folate and B12 serum levels in association with depression in the aged: a systematic review and meta-analysis. Aging \& Mental Health, Vol. 20, No. 9, 965-973, 2016. https://doi.org/10.1080/13607863.2015.1049115

REDDY, M. Depression: The disorder and the burden. Indian Journal of Psychological Medicine, 32(1), 1, 2010. https://doi.org/10.4103/0253-7176.70510 
ROCHA, F. L.; FUZIKAWA, C.; RIERA, R.; HARA, C. Evidências sobre a combinação de antidepressivos na depressão maior. Diagn Tratamento, 18(2):87-93, 2013.

SÁNCHEZ, M. A. P.; ESMER, M. C. S.; MARTÍNEZ, L. V.; VARELA, N. G.; VALDEZ, R. L.; TORRES, R. S.; LÓPEZ, R. O.; VILLARREAL, J. P. Efecto del consumo de harina de maíz fortificada con acido fólico sobre los niveles de folato sanguíneos en mujeres de edad fértil. Rev Chil Nutr Vol. 38, №2, Junho, 2011. http://dx.doi.org/10.4067/S0717-75182011000200008

SANTOS, Q.; SICHIERI, R.; MARCHIONI D. M. L.; VERLY Jr, E. Evaluation of the safety of different doses of folic acid supplements in women in Brazil. Rev Saúde Pública, 47(5):1-6, 2013. http://dx.doi.org/10.1590/S0034$\underline{8910.2013047004769}$

SCAGLIONE, S.; PANZAVOLTA, G. Folate, folic acid and 5methyltetrahydrofolate are not the same thing. Xenobiotica, 44(5): 480-488, 2014. https://doi.org/10.3109/00498254.2013.845705

STOPA, S. R.; MALTA, D. C.; OLIVEIRA, M. M.; LOPES, C. S.; MENEZES, P. R.; KINOSHITA, R. T. Prevalência do autorrelato de depressão no Brasil: resultados da Pesquisa Nacional de Saúde, 2013. REV BRAS EPIDEMIOL, Dez 18 Suppl 2: 170-180, 2015. http://dx.doi.org/10.1590/1980-5497201500060015. 